\title{
Teenager's Preferences and Choice Behavior towards Branded Or Unbranded Products
}

\author{
${ }^{1}$ ShahimiMohtar, ${ }^{2}$ Mazhar Abbas, \\ ${ }^{1}$ University Utara Malaysia \\ ${ }^{2} P h D$ (Student) University Utara Malaysia
}

\begin{abstract}
The focus of this research istowardexamining the teenager's preferences and choice behavior; furthermore assess the preferences of the teens towards branded and unbranded products and their awareness regarding branded/Unbrandedproducts. Information was collected from 320 different school students in Pakistan related to the mature group 13-19 years old. The main purpose of the research was concentrated in the preferred vs. non preferred products. Analysis of databe conducted by using statistical analysis software SPSS. Results showed that a female teenager is more socially influenced, fashion, leisure and puzzled over-choice as compared to male. Young males were found considerably more probable to rely on media, uncompromising worker \& brand conscious and spontaneous customer. The Implications of this research must include parents as well as children; brand marketing should not only for parents, but also the children.
\end{abstract}

Key words:Teenagers, children preferences, choice behavior, awareness

\section{Introduction}

Branded/ unbranded products and teenagers preferences are very important to explain a significant segment The previous study explore the brand consciousness, perceptions, attitudes and adolescents capability to evaluate the brand as the theoretical stage designed for explaining branding from the adolescents point of view. A brand can be defined as "an identifiable product, service, person, or place augmented in such a way that the buyer or user perceives relevant, unique added values which their needs most closely. Furthermore its success results from being able to sustain these added values in the face of competition" (de Chernatony and McDonald, 2003).A prior research (Ross and Harradine, 2007) have explored the difference between actual brand for children and parents. Theresults showed that brand awareness commences by the side ofaprematuretimes than their parents believe. The research examined that young children have increasing capability to collect more information regarding brands and have a capacity in the direction of exercise this information in their buying process. As far as (Ross and Harradine, 2004) determined a few of the associations among adolescent school kids and branding. The results showed that children recognized brand by their premature age with elder age group having better brand consciousness.

The study about the increasing ability of brand awareness between early age group of children is rich. This cohort of young purchaser has increasing brand awareness because they have deep information about brand and preferences. However (Leonhard, 1997;Zinn, 1994) examine that children and adolescents were faithfully his disciples strict brand such as Gap,Nike, and Abercrombie \& Fitch.

Further more kids recognized brands at their earlier ages; precipitating the gap of stores for example restricted Too and Abercrombie Kids in order that the younger set can acquire the same brands accessible to teens (Edgecliffe-Johson, 1999).

Through this wide definition, it is the teenagers buying behavior towards branded/unbranded products and their preferences regarding branded/unbranded products in Pakistani market that are the main purpose of this paper. In Pakistani market teenagers characterize marvelous projection for marketers. According to the Federal Bureau of Statistics (Pakistan) teens represents 40.07\% of total population in 1998 and may increase vigorously in next 10 years. (Latif et al., 2011).

Missing, on the other hand is an examining the of what brand names indicate to kids and how they behave towards branded/unbranded products and what are their preferences about branded/unbranded products in Pakistan. In this paper we obtain initial step in this way through asking a fundamental question: How much do you like the taste of fast food products? We planned that kids are dissimilar ages narrate to brand names in dissimilar behavior. To examine this line of philosophy we commence by relating research in kids psychology that puts light on how children prefer the branded/unbranded products in Pakistani market and what are their purchasing behavior. Based on this substance, we show the hypothesis between the teenagers and branded/non branded products in Pakistani market. 


\section{Literature review}

The study begins through considering the teenager's preferences about branded/unbranded products in Pakistani context and understanding the children attitude and behavior about branded products and also focused on the different generation brand preferences like generation $\mathrm{X}, \mathrm{Y}$ and $\mathrm{Z}$.

Buying pattern of young consumer particularly teenagers is the main focus of researcher in the field of marketing. According to Martin and Bush, (2000) noted that Teenager influence each other's when they adopt particular life styles, building loyal buying model that continue with them all over their mature life and have comparatively greater payments power. Furthermore (Bush et al., 2004) explore that teenagers are striving and searching for their own distinctiveness. Teenage group have significant influence on their ancestors, central customer buying group, in the general public and are of big significance for marketers (Kotler et al., 2005). Additionally Taylor and Cosenza,(2002) found that when the teen age group grows into older consumer, retailer can collect financial rewards connected with a long-term correlation. Chan, (2006) explored the young consumers and their perceptions about brands in Hong Kong aged 13 to 19. Investigation of the results and surveys show the major differences in teenager's awareness of an important person through or throughout package of branded commodities in terms of kind of belongings, free timebehavior, apparent traits and traitsmanners.Achenreiner and John,projected that adolescents relate to brands on a perceptual level, whilebig children relate to brands on a conceptual basis.

They have examined this proposal in an experiment conducted with the children of 8,12 , and 16 years of age. The participants were asked to evaluate product announcements with a familiar brand name, which has either been popular as Nike ${ }^{\circledR}$ or less popular as either Kmart ${ }^{\circledR}$. The product has been physically identical in both cases, enabling them to study the point of whether the mark had meanings for children outside of his name or to the familiarity of the perceptual feature. The use of the conceptual brand meanings has been evaluated by asking participants to perform several types of brand of related judgments, including assessments of advertised products, the prints of the owners of the product promoted and evaluations of possible extensions of the popular brand advertisements. The results have indicated that, at the time the children reach 12 years of age, they use the brand as an important brand of conceptual judgments of consumers. Achenreiner and John, (2003).

However in that article authors discussed the meaning of brand name to children at the age of 8,12 and 16. Pakistani teenagers have its own cultural norms and values and they make selection of product according to their cultural values. This study is not applicable in Pakistan because Pakistani teenagers have their own preferences and choices pertaining branded or unbranded products. Their purchasing aptitude is different from those countries where that research was conducted. Authors used efficient and effective methodology because they categorized the date like gender, age and product category for quick response from the participants.

Retailer has decided that the emerging segmentation and thoughtful of the target group is vital inputs of products differentiation and improve shopping trend. The majority of the purchasing behavior and selection profiling tends to generalized accumulation before useful information on the segment. Therefore, the majority outcome is not practical the targeting and positioning. An analysis was carried out to investigate choice shopping behavior is very essential as well as effective feasible section of this market teenager called as "later female ages teen". This was noted so as to a distinctive character as well as older female youngster is due to shop a influence of the society. This cluster is smelled brand (fit, look and style) to be significant relate mainly to consider in the manufacture of apparel and selection later ages of women adolescents must be enthusiastic in their large purchases. Shopping was imperative and there was of the risks related to aerroneous choice of their clothing. Lastly the wish to hang about and to go shopping at the local shopping center seems to be the purpose of the Mall composition and contentment (Taylor \&Cozenza, (2002).

However in that article authors discussed later aged youngster shopping Mall behavior and choice of clothing but in Pakistan mall shopping and clothing shops are different as compare to USA. Pakistani female teens have relatively same choice behavior but their purchasing aptitude is entirely different from USA. Another view of that article they ranked brand/label was in last in their survey but in our article branded or unbranded ranked at the top of the list. Authors used different methodology which is not applicable in Pakistani culture because their method of collection of data is complicated for the Pakistani teenagers. O'Cass and Choy examined that consumer's fashion clothing participation effect of Chinese generation $\mathrm{Y}$ on particularbrand associated responses plusbrand status, brand attitude and eagerness to disburse a premium for particular brand. The questionnaire was self-administered in China for student's age between 19 and 26 years. Moreover consumer the intensity of the participation was deemed optimistic effect of brand associated answers such as awareness of the status brand and attitude. In addition the brand attitude and status of brand has been investigated to have a positive impact on the consumers is willing to pay a premium for particular brand. Primary as a function sample of the student used for the research it may not be possible to generalize the effects found for non-branded students. Secondly, the results of this research that focused on the fashion clothing brands are perhaps inadequate in their generalizability to different other product categories. A significant result that is 
valuable to the marketing of practitioners in Pakistan, in particular for the fashion industry, is the resultsthat maintain the position building objectives are as a result necessary for enable brands to control increased prices.

However consumer behavior is same but it vary from culture to culture and country to country. In that article authors discussed the Chinese participation in clothing fashion and their brand perceptions and spending patterns. Young Pakistani consumer has same perception as Chinese have for brands and consumer involvement is also similar in this Pakistani culture because of the same consumer behavior. Authors used efficient and effective methodology for the better response.(Hareem Zaib, 2011)Examines the Pakistani women of the consumer purchasing behavior and to understand the key factor of branded clothing which influence the consumption of female participation trend toward branded clothing. A survey was conducted in a general way the consumption of female aged between 13-19 to obtain empirical evidence by using questionnaire and statistical techniques. The total of 320 respondents completed the questionnaires. The results have shown that the status of brand, the brand attitude, paying premium of branded clothing, and the self-concept and the reference group has been found to have positive effects on women consumer buying behavior while increasing consumer participation of clothing to the mode. This paper develops understanding female consumer buying behavior related to Pakistani environment and highlights the factors that strongly influence the consumption participation in clothing to the mode.

However that research is totally conducted in Pakistani context and it is applied in Pakistan related to our research work because authors examined the female consumer buying behavior and involvement regarding branded product. Authors used effective and well-organized methodology by using the questionnaire for quick response by the participants.

\section{Generation X}

This group born between 1965 and 1980. In this generation includes adults and they fall into the age group of 25 and 40 years old (Packaged Facts, 1996). Generation X has better brand consciousness, awareness but they have relatively low brand loyalty because they have large availability of brand choices, additional open to experimentation, the more refined as regards shopping and media, fewer brands advertising once growing up. When they go for shopping they are not care about brand names. They are open to innovative brands and goods, nevertheless once they committed toward brands, it's difficult to make them change (Ritchie 1995). They can be severely loyal to those brands who have earned their concentration., interest and usage.They are further tending a "bundle" of brands (Benezra 1995). They are also enthusiastic to compensate for value or brands that signify actual value for the dollar spent (Dunn 1993).

\section{Generation Y}

This group, born between 1977 and 1994. They are invigorating the American economy (Engebretson, 2004) and presentlyrepresent the leading teen's population in the history of the US (Morton, 2002). Buksa and Mitsis, (2011) found that English language enculturation sub-group Y were found to be more likely engage in POWM recommendation behaviors for endorsed products/services/brands. Generation Y have biggest consumption ability by now, at $\$ 600$ billion a year, furthermore this age group still influencing their parent's expenditures (Kennedy, 2001). Generation Y statistics 76 million physically powerful (Kennedy, 2001) and will consist of $41 \%$ of the population as a result of 2009 (Welles, 1999). Additionally Taylor and Cosenza, (2002) reveal that Generation Y who are the children of baby boomers use family funds, and have the strong authority to influence the spending habits of their parents. Rahman and Azhar, (2011) explore that choice deeds and preferences sets are different each other. The cohort $\mathrm{Y}$ adult's secondary cluster opposing showed loyalty distinctiveness as high in developing market environment in opposition to the recognized insight of little devotion found in urbanized countries. Theseshoppers presently range beginning 14 to 31 years aged and most of these prepared for college (about34\% of generation Y is presently 18-23; as an additional $36 \%$ is $24-30$ years older) (Paul, 2001).Bakewell and Mitchell, (2003) explore the findings was specified that adult female cohort Ys have been acculturated by media that represent rich and luxurious lifestyles. Whereas Herrmann (2004, p. 69) found that men are more probably to view being paid the lowest price as a "sport to be won" and a "competitive game;"

Cohort Y is the children of the "baby boomers" cohort or "cohort" X (Herbig et al., 1993). Fan and Li, (2010) examine that for the purchase decision making children used different type of information sources and adopted different strategies to influence parents to purchase their desired food products as they grew older. 


\section{Generation $\mathbf{Z}$}

However Shergil,et al (2010) examine that young New Zealand shoppers have considerably different price perceptions for foreign brands compared with local. FurthermoreSaraneva and Saaksjarvi, (2008) examine that the emotions practiced by habitual consumers are much more difficult than previously thought. Jones and Reid, (2010) explore that seven of the eight food companies are devoted to children and/or teenagers by their web sites or sections of sites with downloadable resources and wide direct advertising. College and Jaya, (2009) noted that the precise selection of clothing helps them to build an image and uniqueness for themselves because Generation Y are brand conscious.Zeb, et al (2011) found that those customers who perceive higher self perception will usually hold a high level of involvement.Scheweand Noble, (2000) in a research explore that Cohort age groups are argued to share a general and dissimilar social character which isformed by the time as well as practice.Achenreiner and John, (2003) in research findings show that children of dissimilar ages narrate to brand names in dissimilar ways. Dotson and Hyatt,(2005) noted that brand preferences and brand consciousness among children is sensitive at their earlier ages by the enlarged occurrence of brands.Köksal, (2007) examine the consumer behavior and preferences in the children clothing market: many of the consumer purchase clothes for their children at least once in any six month period. There is no defined purchasing time. They normally purchase when they needed. In the context of increasing competition and changing social and economic environment, it becomes essential for the marketers to be customer sloping. Buying deeds of customers in the marketplace plays important role in the strategic marketing development. The recent awareness of consumer behavior has introduced many new dimensions in the marketing philosophy and practices. It is both, relevant and important for every business enterprise to know its customers and understand their buying behavior.

"Family as a consuming and decision making unit is a central phenomenon in marketing and consumer behavior" (Commuri and Gentry, 2000, p. 1). The family still plays a very important mediating function. It combines the individual with a large corporation, or the individual learns various roles adapted for life as an adult (Foxall, 1977). The way in which the children learn to become consumers of our society may be in large part the result of influence of the family (Ward, 1974). Given that the culture exercised a considerable influence on the unity of the family, it is also likely that cultural variables influence the process of socialization of children. A similar influence is observed in other countries as shown in fig. 1.

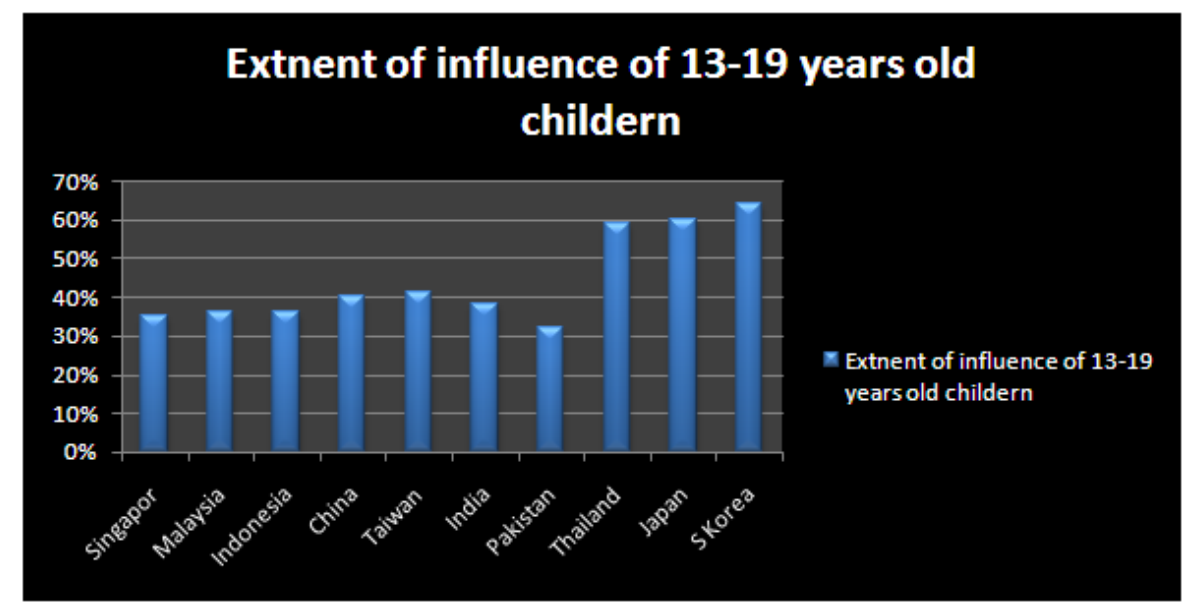

Kumar, S. Children Influence In The Process Of Family Purchase Decision Forhigh, Low And Child-Centric Products, 3(July, 2013), 34-44

\section{Research Methodology}

A study was conducted to examine the spending patterns among young adults. A sample size of 320 participants was chosen studying different universities. Out of 320 participants 167 were male teenagers and 153 were female teenager's shows $52 \%$ and $48 \%$ correspondingly. The student's different schools of Punjab were a target population. The self administered questionnaire provided and filled in questionnaires were collected from the participants and data was entered in computer software (SPSS) for quantitative analysis. Sequentially to find out the consumption manners among young adolescents the un-restricted non probability sampling was used. 


\section{Finding and Implication}

The subsequent investigation based on the study undertaken reflects on the children awareness and attitude towards brand understanding.

Objective 1: To examine teenager's preferences towards branded products

There is high level of resemblance in the attitude of children when children make a decision to buy the brands. In this case brand was very significant feature in purchasing decision through vigorous and value recognized the mainly significant factor.

Though these results are differing since the study undertaken by (Mintel, 2004) that recommended price is much significant feature within purchasing the branded product.

In the survey 67 per cent of teenagers measured the brand labels be significant while making purchases and 15 per cent were neutral with a further 18 per cent declared that brands were unimportant.

This could well be showing the children strong association with branded product. The results also occurs Harper et al.

Objective 2: To identifying the level of awareness about branded product

The outcome indicates that 56.1 per cent children havea elevated level of brands awareness which when compare to the branded/unbranded products. Outcome from Wolvistom School Identified that, once exposed sportswear logos 67 per cent of class 3 (aged 7-8) and 96.55 per cent of class 6 (aged 11-12) acknowledged the brands and the six classes were over 74 per cent. This recommended that understandable brand awareness and attitude of children towards branded products.

Prior study (Ross and Harradine, 2004) analyzed that there were additional mismatches among the awareness of parents and their children brand awareness as the children themselves more influenced by family. This is supported by (Diehl, S., and Karmasin, M. 2013) and (Happer et al, 2003) who noted that for ten to thirteen years olds particular there is strong need for group recognition.

The results might indicate that children level of recognition towards branded product is high in early age.

\section{Conclusion}

Pakistan is a place significance research on this issue. Furthermore, it was stressed that there was no study conducting on Pakistani adolescent consumers' spending style. The discovery of the study is the young adults market within Pakistan, a huge and promising. In this research young adults gender and consumption styles as consumers was analyzed significantly. It shows that young adults are very aware and well conscious about fashion, brand and the use of apparel products and that they takechoice themselves which are based on their environments. The outcome in this study, femaleteenagersis more socially influenced, fashion, leisure and puzzled over-choice as compared to male. Young males were found considerably more probable to reliance on media, uncompromising worker\& brand conscious andspontaneouscustomer.

\section{References}

[1]. Ross, J. Harradine, R. (2004), I am not wearing that! Branding and youth children", Journal of Fashion Marketing and Management, Vol. 8 No. 1, pp. 11-26.

[2]. Ross, J. Harradine, R. (2007), Branding: a generation gap?” Journal of Fashion Marketing and Management, Vol. 11 No. 2, pp. 189200 .

[3]. Kotler, P. Wong, V. Saunders, J. \& Armstrong, G., 2005. Principles of Marketing. Harlow: Pearson.

[4]. Leonhardt, David, \&Kerwin, Kathleen. (1997, June30). Is Madison Avenue taking “get' em while they're young “too far? Business Week, pp.62-67.

[5]. Zinn, Laura. (1994, April 11). Teens: Here comes the biggest wave yet. Business Week, pp. 76-86.

[6]. Edgecliffe-johnson, Andrew. (1999, August 26). Girl power, spending power. Financial Times, p.1

[7]. dechernatony, L. and McDonald, M. (2003), Creating powerful brand in consumer, service and industrial markets, Elsevier Butterworth-Heinemann, oxford.

[8]. Latif, A. Saleem, S. \&Abideen, Z. (2011), Influence of role model on Pakistani urban teenager's purchase behavior. European Journal of Economics, Finance and Administrative Sciences ISSN 1450-2275.

[9]. Chan, K (2006), Young consumers and perceptions of brands in Hong Kong: a qualitative study" , journal of Product \& Brand Management, Vol. 15 Iss: 7 pp. 416-426

[10]. Shergill, G.S, Rosmala, Y and parsons, A.G. (2010), Young New Zealand shopper's brand perceptions and ethnocentricity",International Journal of Retail and Distribution Management, Vol. 38 Iss: 8 pp. 613-624

[11]. Rahman, S. and Azhar, S. (2011), Xpressions of generation Y: Perceptions of the mobile phone service industry in Pakistan", Asia Pecific Journal of Marketing and Logistics, Vol. 23 Iss: 1 pp. 91-107

[12]. Saravena and Saaksjarvi. (2008), Young compulsive buyers and the emotional roller-coaster in the shopping", Young Consumer: Insight and Ideas for Responsible Marketers, Vol. 9 Iss: 2 pp. 75-79

[13]. Jones, S. and Reid, A. (2010), Marketing to children and teens on Australian food company web sites", Young Consumers: Insights and Ideas for Responsible Marketers, Vol. 11 Iss: 1 pp. 57-66

[14]. Zeb, H. Rashid, K and Javeed, M. (2011), Influence of brands on female consumer's buying behavior in Pakistan", International Journal of Trade, Economics and Finance, Vol. 2, No. 3, June 2011 
[15]. Schewe, C.D. and Noble, S.M. (2000), "Marketing Segmentation by Cohorts: The value and validity of cohorts in American and abroad", Journal of Marketing Management, Vol. 16, pp. 129-42

[16]. Herbig, P. Koehler, W. and Day, K. (1993), "Marketing to the baby bust generation", Journal of Consumer Marketing, Vol. 10 No. 1, pp. 4-9

[17]. Bakewell, C and Mitchell, V-W. (2003), "Generation Y female consumer decision-making style “, International of Retail \& Distribution Management, Vol. 31 Iss: 2 pp. 95-106

[18]. Achenreiner, G.B. and John, D.R. (2003). The measuring of brand name to children: A Developmental Investigation. Journal of Consumer Psychology, 13(3), 205-219

[19]. Buksa, I. and Mitsis, A. (2011), "Generation Ys athlete role models perceptions on PWOM behavior", Young Consumer: Insight and Ideas for Responsible Marketers, Vol. 12 Iss: 4pp. 337-347

[20]. Taylor, S.L. and Cosenza, R.M. (2002), "Profiling later aged female teens: mall shoping behavior and clothing choice", Journal of Consumer Marketing, Vol. 19 Iss: 5 pp.393-408

[21]. Fan, Y. and Li, Y. (2010), "children buying behavior in china: A study of information sources", Marketing Intelligence and Planning, Vol. 28 Iss: 2 pp.170-187

[22]. Dotson, M.J. and Hyatt, E.M. (2005), "major influence factors in children's consumer socialization", Journal of Consumer Marketing, Vol. 22 No.1, pp. 35-42

[23]. Köksal, M.H. (2007), "Consumer behavior and preferences regarding children's clothing in Turkey", Journal of Fashion Marketing and Management, Vol. 11 Iss: 1 pp. 69-81

[24]. Taylor, S.L. and Cosenza, R.M. (2002), "Profiling later aged female teens: mall shoping behavior and clothing choice. Journal of Consumer Marketing, 19(5): 393-408

[25]. College, T. and Jaya, P.(2009), "Impact of branding on Gen Y's choice of clothing. The Journal of South East Asia Research Centre for Communications and Humanities. Vol. 1 No.1, pp. 79-95

[26]. Martin, C.A. and Bush, A.J. (2000), "Do role molds influence teenagers purchase intentions and behavior", Journal of Consumer Marketing, Vol. 17 No. 5, pp.441-54

[27]. Bush, A.J. Martin, C.A. and Bush, V.D. (2000), "Sports celebrity influence on the behavioral intentions of Generation Y", Journal Advertising Research, March, pp. 18-17

[28]. Engebretson Joan. Odd Gen out. Am Demogr 2004; 26(4): 14-7

[29]. Morton Linda P. Targeting Generation Y. Public Relate Q 2002;47(2):46-8

[30]. Kennedy Laurel. The up \& coming generation. Retail Merch 2001; 41(8):66.

[31]. Welles, Edward O. The Diva of Retail. Inc. 1999; 21(14): 36-49

[32]. Paul Pamela. Getting inside Gen Y. Am Demogr 2001;23(9):42-9

[33]. Herrmann Gretchen M. Haggling spoken here: gender, class, and style in us garage sale bargaining. J Pop Cult 2004;38(1):55-81

[34]. Packaged Facts. (1996). Generation X Market. MarketResearch.com

[35]. Richie, Karen (1995), Marketing to Generation X. New York: Lexington Books.

[36]. Benezra, Karen (1995a), “Don’t Mislabel Gen X," Brandweek, (May 15), 32, 34.

[37]. Dunn, William (1993), The Baby Bust: A Generation comes of Age. New York: American Demographic Books.

[38]. Achenreiner Gwen B, \& John Deborah Reodder. (2003). the meaning of brand names to children: A developmental investigation. Journal of Consumer Psychology, 13(3), 205-219

[39]. Susan Lee Taylor, Robert M. Cosenza, (2002), "Profiling later aged female teens: mall shopping behavior and clothing choice," Journal of Consumer Marketing, Vol. 19 Iss: 5pp. 393-408

[40]. AronO'Cass, Eric Choy, (2008), "Studying Chinese generation Y consumers' involvement in fashion clothing and perceived brand status", Journal of Product \& Brand Management, Vol. 17 Iss: 5 pp. 341-352

[41]. Hareem zaib, K. R. (2011). Influence of Brands on Female Consumer"s Buying. International Journal of Trade, Economics and Finance, Vol. 2, No. 3, June 2011 .

[42]. Kumar, S. (3July 2013), Children Influence in the Process of Family Purchase Decision for High, Low and Child-Centric Products, 3(July, 2013) pp. 34-44

[43]. Mintel (2004), Marketing to Children Aged 7-10, April, Mintel, London.

[44]. Ross, J. and Harradine, R. (2004), "I'm not wearing that! Branding and young children", Journal of Fashion Marketing and Management, Vol. 8 No. 1, pp. 11-26.

[45]. Harper, S.J.A., Dewar, P. and Diack, B.A. (2003), “The purchase of children's clothing - who has the upper hand?", Journal of Fashion Marketing and Management, Vol. 7 No. 2, pp. 196-206

[46]. Diehl, S., and Kamasin, M (2013) Media and Convergence Management. Berlin: Springer 